\title{
SBSE(EG-Silicone)-UFLC-MS/MS and HPLC-Flu Analysis of Norharman in Passiflora edulis Rinds
}

\author{
Vitor F. Freire, ${ }^{\circledR a}$ Renata Colombo ${ }^{\circledR b}$ and Janete H. Yariwake ${ }^{\circledR *, a}$ \\ ${ }^{a}$ Instituto de Química de São Carlos, Universidade de São Paulo (USP), \\ CP 780, 13560-970 São Carlos-SP, Brazil \\ ${ }^{b}$ Escola de Artes, Ciências e Humanidades, Universidade de São Paulo (USP), \\ 03828-000 São Paulo-SP, Brazil
}

\begin{abstract}
Previous studies on Passiflora edulis (sour passion fruit) rinds reported some biological activities and there is a growing interest on rinds flour as a possible functional food, but its alkaloid composition was not detailed investigated. This work reports on for the first time in the literature the identification of norharman in $P$. edulis rinds, by using stir bar sorptive extraction combined with ultra-fast liquid chromatography coupled to tandem mass spectrometry [SBSE(EG-Silicone)UFLC-MS/MS)]. This $\beta$-carboline alkaloid is suspected to be neurotoxic. Therefore, another purpose of this study was to develop methods of targeted quantification of norharman in P. edulis rinds extracts using polydimethylsiloxane as stationary phase (SBSE(PDMS)) and a copolymer of polydimethylsiloxane and polyethylene glycol as stationary phase (SBSE(EG-Silicone)) combined with high performance liquid chromatography with fluorescence detection (HPLC-Flu) and ultra-fast liquid chromatography coupled with tandem mass spectrometry (UFLC-MS/MS). Norharman extraction by SBSE(PDMS) and SBSE(EG-Silicone) was optimized and compared, and the analytical performance of SBSE(EG-Silicone) method was superior to that of SBSE(PDMS). The analysis of a sample of dried P. edulis rind indicated (332.16 \pm 8.43$) \mathrm{pg} \mathrm{g}^{-1}$ of norharman.
\end{abstract}

Keywords: $\beta$-carboline alkaloids, sour passion fruit, SBSE, rinds

\section{Introduction}

Passion fruit (Passiflora edulis) is a tropical fruit, widely consumed and distributed around the world. In Brazil, it is widely cultivated and used in the food industry (processed juices), therefore generating substantial amounts of rinds as waste product. Therefore, some studies focused on the utilization of rinds as alternative raw material for human and animal food. ${ }^{1,2}$ Studies on the use of passion fruit rinds, as passion fruit flour, as a bioactive food have reported a variety of effects, such as antioxidant activity, ${ }^{3}$ increase in short-chain fatty acids, ${ }^{4}$ reduction of pain and stiffness, and improved physical function of adult patients with knee osteoarthritis, ${ }^{5}$ reduced wheezing and coughing, and improved breathing in adults with asthma, ${ }^{6}$ and lowering of blood pressure in hypertensive female rats and humans. ${ }^{7}$ However, the chemical composition of passion fruit rinds still needs to be investigated, since most of the studies about the biological properties of Passiflora rinds extracts have

*e-mail: janete@iqsc.usp.br explored their flavonoid composition. ${ }^{8,9}$ More recently, the identification of $\beta$-carboline alkaloids in Passiflora was investigated using a modern analytical approach by means of stir bar sorptive extraction with liquid chromatography (SBSE/LC) and mass spectrometry (MS) techniques. ${ }^{10,11}$

Earlier studies have reported $\beta$-carboline alkaloid constituents in $P$. incarnata. ${ }^{12}$ These compounds contain the $9 H$-pyrido $[3,4-b]$ indole skeleton (also called $\beta$-carboline, and known by the common names of norharman or norharmane). Figure 1 depicts the equilibrium of norharman forms, according to the $\mathrm{pH}$ and its $\mathrm{p} K_{\mathrm{a}}{ }^{13}$ and gives theoretical $^{14}$ and experimental ${ }^{15} \log K_{\mathrm{O} / \mathrm{W}}$ values.

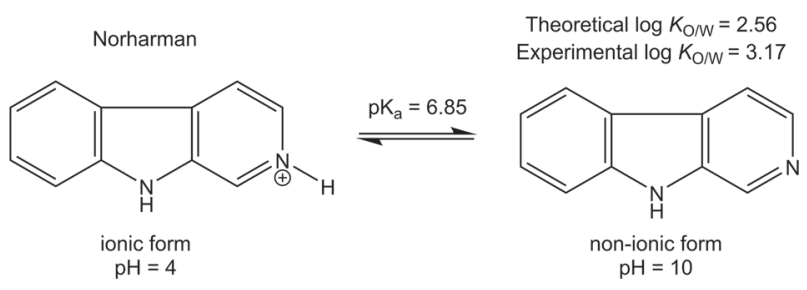

Figure 1. Schematic diagram of the effect of $\mathrm{pH}$ on norharman ionization equilibrium. 
In recent years, interest in the investigation of norharman has increased due to its occurrence in food and in environmental samples, and because it is also an endogenous compound in the human body.,16-19 Norharman is considered an endogenous neurotoxin that induces idiopathic Parkinson's disease $\mathrm{e}^{20,21}$ and there are reports linking this compound to various biochemical, pharmacological and toxic effects, ${ }^{22}$ suggesting that this compound may be neurotoxic. These reports show the importance in the development of methods for identification and quantification of norharman for the study P. edulis rinds as a source of this compound.

Due to the very low amounts of the $\beta$-carboline alkaloids presented in Passiflora species, the stir bar sorptive extraction (SBSE) was already proved as good for the clean-up, pre-concentration, and fast sample preparation technique. ${ }^{10,11}$

SBSE is a sample preparation technique that involves the simultaneous extraction and concentration of analytes. This microextraction technique requires small quantities of organic solvents and small amounts of samples, thus enabling faster sample preparation, which is consistent with the principles of green chemistry. Although the analysis of complex matrices is still a challenging task, the emergence of sorption-based methods has enabled direct microextraction from complex matrices. The SBSE analytical devices consist of glass-encapsulated magnetic stir bars coated with a polymeric phase, which acts as the extraction phase. ${ }^{23-25}$

Two different polymeric phases are commercially available today: polydimethylsiloxane, designated SBSE(PDMS) in this paper, and a copolymer of polydimethylsiloxane and polyethylene glycol, sold by Gerstel under the brand name EG-Silicone Twister ${ }^{\circledR},{ }^{26}$ designated in this paper SBSE(EG-Silicone). SBSE(PDMS), the most widely used commercial phase, whose sorption theory has been exhaustively explored, is a non-polar phase that promotes Van der Waals interactions with the targeted analytes. ${ }^{24}$ SBSE(EG-Silicone) phase, on the other hand, is still being investigated. The theory about the extraction process of the latter is not yet as complete as that of the SBSE(PDMS) phase, but this copolymer has proved to be a useful choice for the extraction of intermediate polarity compounds $\left(\log K_{\mathrm{o} / \mathrm{w}}>3\right) \cdot{ }^{27-29} \mathrm{In}$ addition to the range of possibilities offered by the two different commercially available polymeric phases, SBSE also allows for the adjustment of some variables in the extraction medium, such as ionic strength and the addition of organic and $\mathrm{pH}$ modifiers. Moreover, the combination of ideal conditions results in an efficient extraction of compounds with different polarities. ${ }^{27-29}$ These conditions can be optimized through univariate analysis (which usually requires a large number of experiments and does not allow the correlation between the factors or multivariate analysis to be evaluated). Multivariate analysis using factorial design allows the simultaneous evaluation of the effects of numerous factors, based on a small number of experimental trials. Experimental design is also a powerful tool for statistical analysis, facilitating the interpretation of results for the optimization of methods. ${ }^{30}$

Given that SBSE is easy to couple with chromatographic techniques, it may also yield very good results in trace element analysis, since selectivity and sensitivity are enhanced. ${ }^{31,32}$ In this work, the advantages of SBSE were combined with HPLC-Flu (high performance liquid chromatography with fluorescence detection) and UFLC-MS/MS (ultra-fast liquid chromatography coupled with tandem mass spectrometry), to study Passiflora edulis rinds extracts. HPLC-Flu combines the high selectivity and sensibility of the fluorescence detector with the good separation provided by HPLC for complex matrix..$^{10,11}$ The evolution of hyphenated techniques such as UFLC-MS/MS includes the combination of UFLC ${ }^{\circledR}$ (and also the alternative brand name UPLC ${ }^{\circledR}$, ultra-performance liquid chromatography, and UHPLC, ultra-high performance liquid chromatography) together with the development of different strategies of mass spectrometry, such as SRM (single reaction monitoring), which enable more in-depth investigations into the minor compounds in complex samples such as plant extracts and foods. ${ }^{16}$

Considering the potentially toxic effects of $\beta$-carboline alkaloids, this study focuses on the targeted analysis of norharman (identification and quantification) in Passiflora edulis rinds, using SBSE, HPLC-Flu and UFLC-MS/MS, in the SRM mode. This is also the first report of norharman in P. edulis.

\section{Experimental}

\section{Chemicals and materials}

Methanol, acetonitrile and ethanol were HPLC grade, purchased from Tedia (Fairfield, OH, USA). Formic acid, sodium chloride, ammonium chloride and ammonium hydroxide were purchased from Merck (Darmstadt, Germany). Water was purified in a Milli-Q system (Millipore, Bedford, MA, USA). Norharman (98\% purity) standards were purchased from Sigma-Aldrich (Steinheim, Germany). Commercial stir bars for sorptive extraction (Twister ${ }^{\mathrm{TM}}$ ) were supplied by Gerstel (Mulheim an der Ruhr, Germany) and consisted of glass-encapsulated magnetic stir bars. For SBSE(PDMS), $20 \mathrm{~mm}$ long and 
$0.5 \mathrm{~mm}$ film thickness, coated with $47 \mu \mathrm{L}$ of PDMS (code 011444-001-00). For SBSE(EG-Silicone), $10 \mathrm{~mm}$ long, coated with $32 \mu \mathrm{L}$ of a copolymer of PDMS and EG-Silicone (code 016904-001-00). Prior to their first use, the stir bars were heated for $2 \mathrm{~h}$ at $300^{\circ} \mathrm{C}$ under a nitrogen stream. After that, the stir bars were conditioned for $72 \mathrm{~h}$ by stirring with methanol and dichloromethane $(50: 50 \mathrm{v} / \mathrm{v})$.

\section{Plant samples}

Samples of fresh passion fruit (Passiflora edulis) were purchased in a local supermarket in São Carlos, São Paulo State, Brazil, in August 2016. To prepare the rinds samples, all fruits were cut open with a knife and the rinds were separated from the pulp and seed with a spoon. The rinds were dried in a conventional laboratory oven without forced ventilation at $35-40^{\circ} \mathrm{C}$ until constant weight (around $72 \mathrm{~h}$ ). After dried, the rinds were triturated in a domestic blender and ground; only particles below $1.00 \mathrm{~mm}$ were utilized for extractions.

\section{Optimization of sample preparation}

SBSE(PDMS) and SBSE(EG-Silicone) were evaluated for extraction of norharman by using fractional factorial design $2^{5-1}$, (16 trials plus 3 central points) experiments were carried out in triplicate in random order. The software Minitab $^{\circledR}$ v. $13^{33}$ was used for the statistical analysis.

The levels of the factors were chosen based on the Gerstel's instructions for stir bar users and also considering other publications about SBSE..$^{10,27-29,34}$ Experiments were conducted to evaluate the influence and interaction of five selected factors, at three levels each: $\mathrm{pH}(4,7$ and 10), time of extraction (30,90 and $120 \mathrm{~min}$ ), percentage of methanol $(0.50,2.75$ and $5.00 \%)$, percentage of $\mathrm{NaCl}(0,15$ and $30 \%)$ and total sample volume (3.0, 6.5 and $10.0 \mathrm{~mL})$. The $\mathrm{pH}$ level was adjusted to keep it at 4, using a solution of $\mathrm{HCl}$ $\left(0.0001 \mathrm{~mol} \mathrm{~L}^{-1}\right)$; and at $\mathrm{pH}=10$ during the extraction using a buffer solution of $\mathrm{NH}_{4} \mathrm{OH} / \mathrm{NH}_{4} \mathrm{Cl}(\mathrm{pH}=11)$. In both cases, the amount of these solutions was limited to $10 \%$ of the total solution volume. Experiments were conducted by using a standard solution of norharman, at the concentration of $5.00 \mu \mathrm{g} \mathrm{L}{ }^{-1}$. After the extraction was performed, the stir bars were removed from the sample solution, rinsed with purified water and carefully dried with a lint-free tissue and then immersed in a vial containing $150 \mu \mathrm{L}$ of the desorption solvent. The desorption process was initially performed with $60 \mathrm{~min}$ of sonication (ultrasonic bath) evaluating methanol, acetonitrile, ethanol, and mixtures of ethanol/water (30:70 v/v and 70:30 v/v, all in $\mathrm{pH} 4)$ and mixtures of methanol/water $(30: 70 \mathrm{v} / \mathrm{v}$ and $70: 30 \mathrm{v} / \mathrm{v}$, all in $\mathrm{pH} 4$ ) as desorption solvent. Once the solvent was chosen, time desorption was evaluated by plotting a curve time versus percentual recovery, using $150 \mu \mathrm{L}$ of methanol as desorption solvent. The different times of desorption evaluated were 2.5, 10.0, 15.0, 30.0 and $60.0 \mathrm{~min}$. After desorption, the stir bar was removed and the solution was directly analyzed by LC-Flu. The response used for evaluating all optimization procedures was the recovery of the analyte, calculated using the formula in equation 1.

$R(\%)=\frac{A_{E}}{A_{T}} \times 100$

where, $A_{E}=$ experimental area $=$ area of the analyte after the extraction, and $\mathrm{A}_{\mathrm{T}}$ is:

$\mathrm{A}_{\mathrm{T}}=$ Theoretical area $=\frac{\left(\begin{array}{c}\text { area of the analyte } \\ \text { before extraction }\end{array}\right) \times\left(\begin{array}{c}\text { total sample } \\ \text { volume (L) }\end{array}\right)}{\text { volume of desorption }(\mathrm{L})}$

The cleaning of the stir bars was performed by sonication in $1.8 \mathrm{~mL}$ of methanol, during $60 \mathrm{~min}$.

\section{Chromatographic HPLC-Flu analysis conditions}

HPLC-Flu analysis were carried out with a Waters Alliance 2695 liquid chromatography (Waters, Milford, MA, USA) coupled to a Waters 2475 fluorescence photodiode array detector (Flu/PAD), controlled by Waters Empower 2 software. The separation was performed using a Waters X-Terra ${ }^{\circledR} \mathrm{C} 18$ column $(250 \times 4.6 \mathrm{~mm}$ internal diameter, i.d., $5 \mu \mathrm{m}$ ) preceded by an X-Terra ${ }^{\circledR} \mathrm{C} 18$ guard column $(20 \times 4.0 \mathrm{~mm}$ i.d., $5 \mu \mathrm{m})$, also from Waters. Chromatographic conditions were: $0.5 \%$ formic acid in acetonitrile (solvent $\mathrm{A}$ ) and $0.5 \%$ formic acid in water (solvent B). The gradient was programed from 20 to $34 \%$ A for $10 \mathrm{~min}$, and 34 to $20 \% \mathrm{~A}$ for $18 \mathrm{~min}$. The flow rate was $1 \mathrm{~mL} \mathrm{~min}^{-1}$, the column temperature was $25^{\circ} \mathrm{C}$ and the injection volume was $10 \mu \mathrm{L}$. To detect norharman, the fluorescence detector was set at $\lambda_{\text {excitation }}=254 \mathrm{~nm}$ and $\lambda_{\text {emission }}=440 \mathrm{~nm}$. The alkaloids were identified in passion fruit samples by direct comparison with standards (fluorescence and UV spectra and retention time). These chromatographic conditions were based on the method developed by Pereira et al. ${ }^{10}$

\section{Chromatographic LC-MS/MS analysis conditions}

LC-MS/MS analyses were carried out with a Shimadzu UFLC-20AXR liquid chromatography (Kyoto, Japan) coupled to a Shimadzu LCMS-8030 triple quadrupole mass 
spectrometer. The separation was performed using a Kinetex ${ }^{\circledR}$ (Phenomenex, Torrance, USA) $\mathrm{C} 18$ column $(50 \times 3 \mathrm{~mm}$ i.d., $2.6 \mu \mathrm{m})$. Chromatographic conditions were: $0.1 \%$ formic acid in water (solvent A) and acetonitrile (solvent B). The gradient was programmed from 9 to $13 \% \mathrm{~B}$ for $2.5 \mathrm{~min} ; 13$ to $14 \%$ B for $2.6 \mathrm{~min} ; 14$ to $15 \%$ B for $4.0 \mathrm{~min} ; 15$ to $20 \%$ B for $5 \mathrm{~min}$; and 20 to $50 \% \mathrm{~B}$ for $10 \mathrm{~min}$. The flow rate was $0.4 \mathrm{~mL} \mathrm{~min}{ }^{-1}$, the column temperature was $40{ }^{\circ} \mathrm{C}$ and the injection volume was $10 \mu \mathrm{L}$. The nitrogen was the nebulizing and drying gas (flow rate 3 and $15 \mathrm{~L} \mathrm{~min}^{1}$, respectively). The temperature of dessolvation line was $250^{\circ} \mathrm{C}$ and heat block temperature was $400{ }^{\circ} \mathrm{C}$. Argon was employed as collision gas. The collision energy, Q1 pre-rod bias and Q3 pre-rod bias voltages were respectively: $37.0 ; 11.0$ and $-13.0 \mathrm{~V}$ (transitions $m / z 169.0>115.1$ ) and $-10.0 ; 16.0$ and $-15.0 \mathrm{~V}$ (transitions $\mathrm{m} / \mathrm{z} .169 .0>128.3$ ).

\section{Analytical performance}

The analytical performance of the SBSE(EG-Silicone)HPLC-Flu method was evaluated using passion fruit rinds spiked with different aliquots of a norharman standard stock solution $1000.00 \mu \mathrm{g} \mathrm{L}^{-1}$ in methanol, considering linearity, precision, accuracy, limit of detection (LOD) and limit of quantification (LOQ). Linearity was estimated by the correlation coefficient $\left(\mathrm{R}^{2}\right)$ of a plotted analytical curve, using passion fruit rinds spiked with five levels of concentrations: $0.50,5.00,10.00,15.00$ and $20.00 \mu \mathrm{g} \mathrm{L}-1$. Accuracy and precision were estimated by evaluating recovery and repeatability in triplicate at the same day. Spiked samples at three levels of concentration $(0.50,10.00$ and $20.00 \mu \mathrm{g} \mathrm{L}^{-1}$ ) were analyzed in triplicate. Accuracy was expressed in recovery according to equation 1 and relative standard deviations (RSD) of the analysis were used to express the precision. LOD and LOQ were estimated experimentally by direct injection of the standard solution of norharman diluted in methanol until the signal-to-noise ratio for the standard reached a 3:1 ratio for LOD and 10:1 for LOQ.

In order to evaluate the matrix effect, experiments were performed by spiking different amounts of $P$. edulis rinds (100 and $50 \mathrm{mg}$ samples) with a standard solution of norharman standard (1000,0 $\mu \mathrm{g} \mathrm{L}^{-1}$, in methanol) in order to achieve the final concentration of $5.00 \mu \mathrm{g} \mathrm{L}^{-1}$. Spiked rinds samples were extracted and the recovery rate of the norharman was calculated.

\section{Analysis of norharman in passion fruit rinds}

$50 \mathrm{mg}$ of passion fruit rinds were put into a vial with $900 \mathrm{mg}$ of $\mathrm{NaCl}, 2.550 \mathrm{~mL}$ of Milli-Q water,
$150 \mu \mathrm{L}$ of methanol and $300 \mu \mathrm{L}$ of a buffer solution of $\mathrm{NH}_{4} \mathrm{OH} / \mathrm{NH}_{4} \mathrm{Cl}$ (to ensure $\mathrm{pH}$ 10). The extraction was performed by using the EG-Silicone stir bars during $120 \mathrm{~min}$ at room temperature. After the extraction, the stir bar was removed from the vial, rinsed with purified water and carefully dried with a lint-free tissue. The analyte was desorbed in a vial containing $150 \mu \mathrm{L}$ of methanol during $15 \mathrm{~min}$ in an ultrasonic bath. After desorption, the stir bar was removed and the methanol solution was directly analyzed by HPLC-Flu and UFLC-MS/MS.

The quantification of norharman in passion fruit rinds was performed by HPLC-Flu, by using standard addition method. An analytical curve was built by extracting plant samples spiked with a stock solution of norharman in methanol $\left(100.00 \mu \mathrm{g} \mathrm{L}^{-1}\right)$ to reach final concentrations of $0.25,0.38,0.50,0.63$ and $0.75 \mu \mathrm{g} \mathrm{L}^{-1}$. The amount of norharman was calculated based on the linear equation and the intercept on $x$-axis of the analytical curve and using peak area. Data were expressed as the (mean \pm standard deviation).

\section{Results and Discussion}

\section{Identification of norharman in P. edulis rinds by UFLC-MS/MS} analysis

The first assays of $P$. edulis rinds, which were performed in order to select the target compound to optimize sample preparation and quantitative analysis conditions, suggested that the major compound was an alkaloid not yet described in P. edulis. The fluorescence spectra of this compound showed $\lambda_{\max }=440 \mathrm{~nm}$ and a profile that suggested the $\beta$-carboline alkaloid norharman. Since this compound had not previously been identified in $P$. edulis, its identity was investigated by MS/MS before the quantitative analytical method was optimized.

The analysis of a standard norharman by UFLC-MS/MS in the SRM mode enabled the identification of the $\mathrm{m} / \mathrm{z} 169.0>115.1$ and $\mathrm{m} / \mathrm{z} 169.0>128.3$ transitions (Figure 2). The suggested structure of the fragments was based on the fragmentation route proposed in the literature. ${ }^{35}$ The Passiflora extracts were analyzed after determining which transitions should be monitored based on an analysis of the standard solution of norharman.

P. edulis fruit rinds were extracted by SBSE(EG-Silicone), as described in the Experimental section, prior to the UFLC-MS/MS analysis. The characteristic transitions for norharman were monitored in SRM mode at a peak in the same $t_{R}(3.80 \mathrm{~min})$ of the standard, providing unequivocal confirmation of the presence of norharman. This is the first report of norharman in P. edulis. 


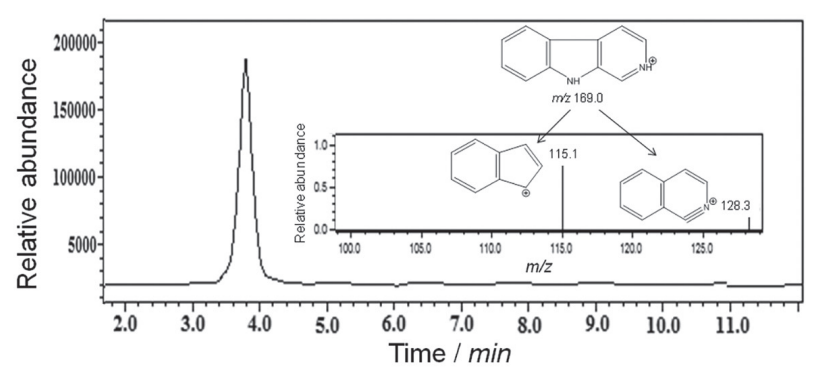

Figure 2. Chromatogram and transitions of norharman observed in SRM mode in the SBSE(EG-Silicone)-UFLC-MS/MS analysis.

\section{Optimization of SBSE sample preparation}

Multivariate experimental design is a useful tool for the optimization of parameters, considering a reasonable number of experiments and associations of factors. ${ }^{30,36}$ Therefore, the use of SBSE(PDMS) and SBSE(EG-Silicone) for the extraction of norharman was evaluated by means of $2^{5-1}$ fractional factorial design. Table 1 describes the matrix of experiments and the response obtained for each experiment. Several parameters were chosen, also considering the manufacturer's recommendations regarding SBSE(EG-Silicone) stir bars. The $\mathrm{pH}$ level was evaluated between $\mathrm{pH} 4$ to 10 due to the $-\mathrm{OH}$ groups of the polymer; the optimization was therefore done respecting these maximum levels. In view of the recommendations of the $\mathrm{NaCl}$ manufacturer to avoid undissolved solids in the extracted samples and long extraction times in the presence of solid material, the highest percentage of $\mathrm{NaCl}$ used here was $30 \%(\mathrm{~m} / \mathrm{v})$ and the longest extraction time was $120 \mathrm{~min}$, thereby preventing mechanical damage of the polymeric coating. The percentage of methanol was evaluated between 0.50 and $5.00 \%$ because a minimum of methanol had to be in solution, since the norharman solution was prepared in methanol. However, large quantities of methanol may decrease the recovery of the analytes of intermediate and high polarity. Therefore, a total sample volume was chosen for evaluation in order to ascertain its influence on the recovery rate, and levels of 3.0 and $10.0 \mathrm{~mL}$ were chosen based on preliminary tests.

Table 1 describes the results of the 19 experiments of the two SBSE coatings that were performed using the factorial design for norharman recovery. These results were evaluated using a Pareto chart (which indicates which factor has the strongest effect on the recovery, Figure 3), a main effects graph (which shows variations in response as a function of evaluated levels, Figure 4), and graph of interaction between factors (Figure 5). According to the Pareto chart, the factors that exert the greatest influence on the norharman extraction process by the PDMS phase

Table 1. Matrix of experiments in fractional factorial design for the optimization of norharman extraction by SBSE(PDMS) and SBSE(EG-Silicone)

\begin{tabular}{|c|c|c|c|c|c|c|c|}
\hline Run order & $\mathrm{pH}$ & $\begin{array}{l}\text { Extraction } \\
\text { time / min }\end{array}$ & $\begin{array}{l}\text { Percentage of } \\
\text { methanol / \% }\end{array}$ & $\begin{array}{c}\text { Percentage of } \mathrm{NaCl} \\
/ \%\end{array}$ & $\begin{array}{l}\text { Total sample } \\
\text { volume / } \mathrm{mL}\end{array}$ & $\begin{array}{l}\text { Recovery } \\
\text { PDMS / \% }\end{array}$ & $\begin{array}{c}\text { Recovery } \\
\text { EG-Silicone / \% }\end{array}$ \\
\hline 1 & 10 & 120 & 0.50 & 0 & 10.0 & 13.18 & 17.03 \\
\hline 2 & 4 & 30 & 0.50 & 30 & 3.0 & 0.45 & 2.11 \\
\hline 3 & 10 & 30 & 5.00 & 0 & 10.0 & 3.45 & 10.01 \\
\hline 4 & 7 & 75 & 2.75 & 15 & 6.5 & 7.40 & 20.40 \\
\hline 5 & 4 & 120 & 0.50 & 0 & 3.0 & 0.24 & 5.71 \\
\hline 6 & 4 & 30 & 5.00 & 30 & 10.0 & 0.09 & 0.68 \\
\hline 7 & 4 & 120 & 5.00 & 0 & 10.0 & 0.12 & 1.67 \\
\hline 8 & 10 & 30 & 0.50 & 0 & 3.0 & 14.35 & 21.48 \\
\hline 9 & 4 & 30 & 0.50 & 0 & 10.0 & 0.07 & 3.13 \\
\hline 10 & 7 & 75 & 2.75 & 15 & 6.5 & 7.59 & 20.68 \\
\hline 11 & 4 & 120 & 5.00 & 30 & 3.0 & 0.08 & 2.85 \\
\hline 12 & 10 & 120 & 5.00 & 0 & 3.0 & 18.75 & 38.72 \\
\hline 13 & 4 & 120 & 0.50 & 30 & 10.0 & 0.03 & 1.12 \\
\hline 14 & 10 & 120 & 0.50 & 30 & 3.0 & 56.92 & 67.36 \\
\hline 15 & 7 & 75 & 2.75 & 15 & 6.5 & 7.49 & 20.90 \\
\hline 16 & 4 & 30 & 5.00 & 0 & 3.0 & 0.12 & 2.74 \\
\hline 17 & 10 & 30 & 5.00 & 30 & 3.0 & 37.27 & 42.81 \\
\hline 18 & 10 & 30 & 0.50 & 30 & 10.0 & 24.80 & 24.70 \\
\hline 19 & 10 & 120 & 5.00 & 30 & 10.0 & 29.04 & 33.81 \\
\hline
\end{tabular}

PDMS: polydimethylsiloxane. 

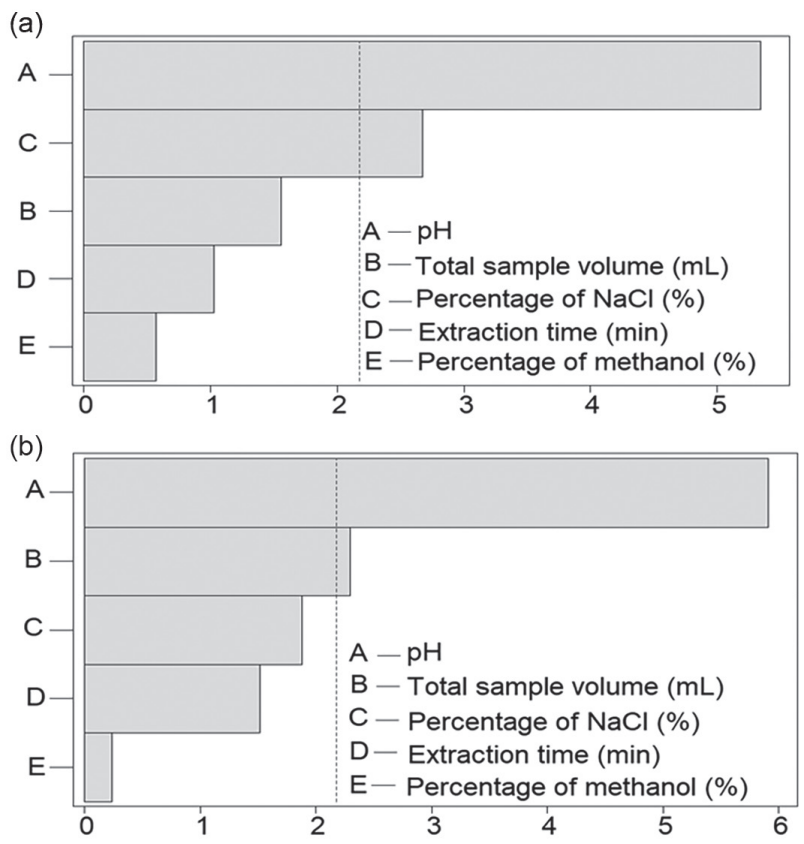

Figure 3. Pareto chart for PDMS (a) and for EG-Silicone SBSE (b) coatings.

are $\mathrm{pH}$ and percentage of $\mathrm{NaCl}$ (Figure 3a). On the other hand, in the case of EG-Silicone phase, the main factors are $\mathrm{pH}$ and total sample volume (Figure $3 \mathrm{~b}$ ).

The significant influence of $\mathrm{pH}$ on the extraction process can be attributed to the presence of the pyridine group $\left(\mathrm{p} K_{\mathrm{a}}=6.65\right)^{13}$ in norharman, since the non-ionic form interacts more strongly with the polymeric phase than with the ionic one (Figure 1). The mechanism of interaction between the polymer and the analyte is also an important factor that affects the extraction process: the sorption of the analyte by SBSE(PDMS) stir bars is an equilibrium process of the analyte between the aqueous phase and the polymer phase $\left(K_{\mathrm{PDMS} / \mathrm{W}}\right)$, and this process behaves very similarly to the process of octanol-water partition $\left(K_{\mathrm{O} / \mathrm{w}}\right)$. The PDMS coating is commonly described as providing good recovery rates with apolar analytes $\left(\log K_{\mathrm{O} / \mathrm{W}}>4\right)$, while recovery rates increase in the case of analytes with $\log K_{\mathrm{O} / \mathrm{W}}<4$ with the addition of $\mathrm{NaCl}^{25}$

The mechanisms of the extraction process using SBSE(EG-Silicone) stir bars are not yet fully understood. In fact, EG-Silicone is a copolymer of PDMS and EG-Silicone, and compared to SBSE(PDMS), this copolymeric coating provides better recovery rates for analytes with lower $\log K_{\mathrm{O} / \mathrm{w} w}{ }^{27-29}$ Since norharman has a theoretical $\log K_{\mathrm{O} / \mathrm{w}}$ of 2.56 (predicted by using ChemBioDraw Ultra v. 13.0) ( $^{37}$ and an experimental $\log K_{\mathrm{O} / \mathrm{W}}$ of $3.17,{ }^{15}$ it was considered a potential analyte for SBSE(EG-Silicone). The accuracy of this prediction was confirmed by the overall experimental results of this work.

The main effects graphs (Figure 4) of both coatings showed significant differences in the response of the factors $\mathrm{pH}$, percentage of $\mathrm{NaCl}$ and total sample volume throughout the variation in $\mathrm{pH}$ levels. Both PDMS and EG-Silicone coatings showed higher recovery rates in response to the increase in $\mathrm{NaCl}$ percentage, with the
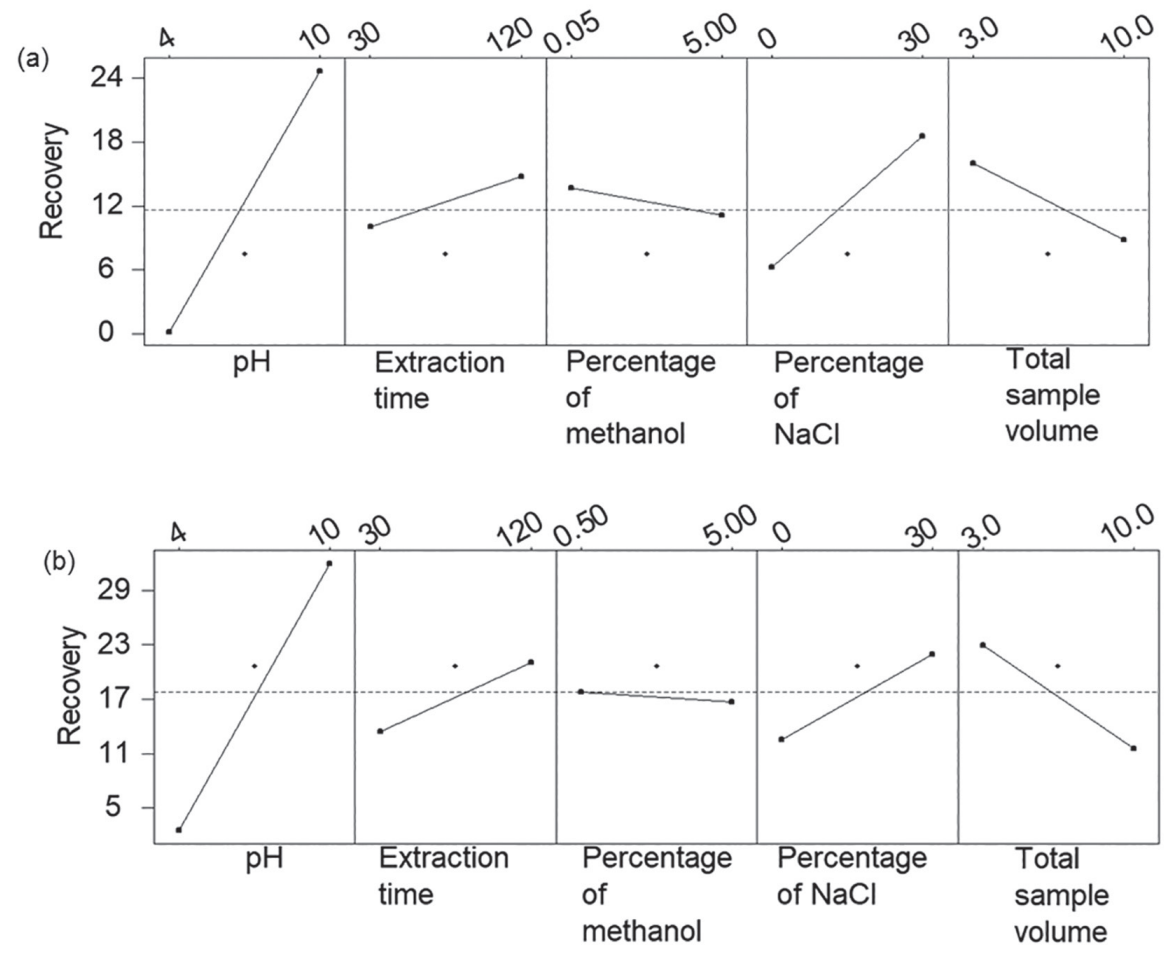

Figure 4. Main effects graphics: (a) SBSE(PDMS) and (b) SBSE(EG-Silicone). 
(a)

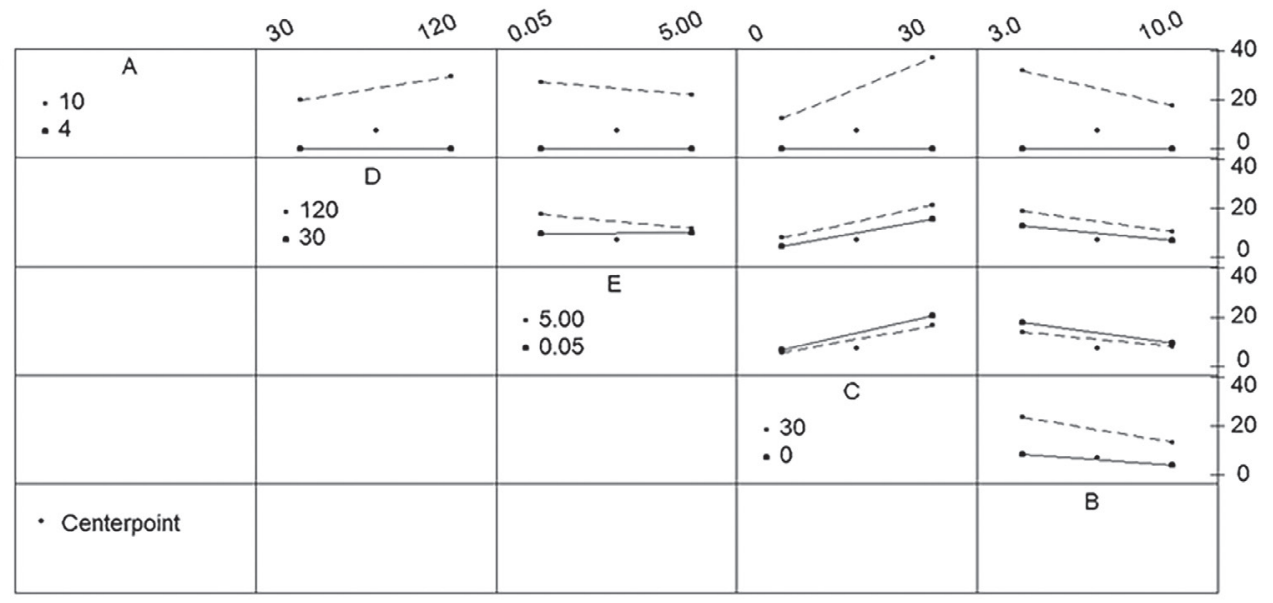

(b)

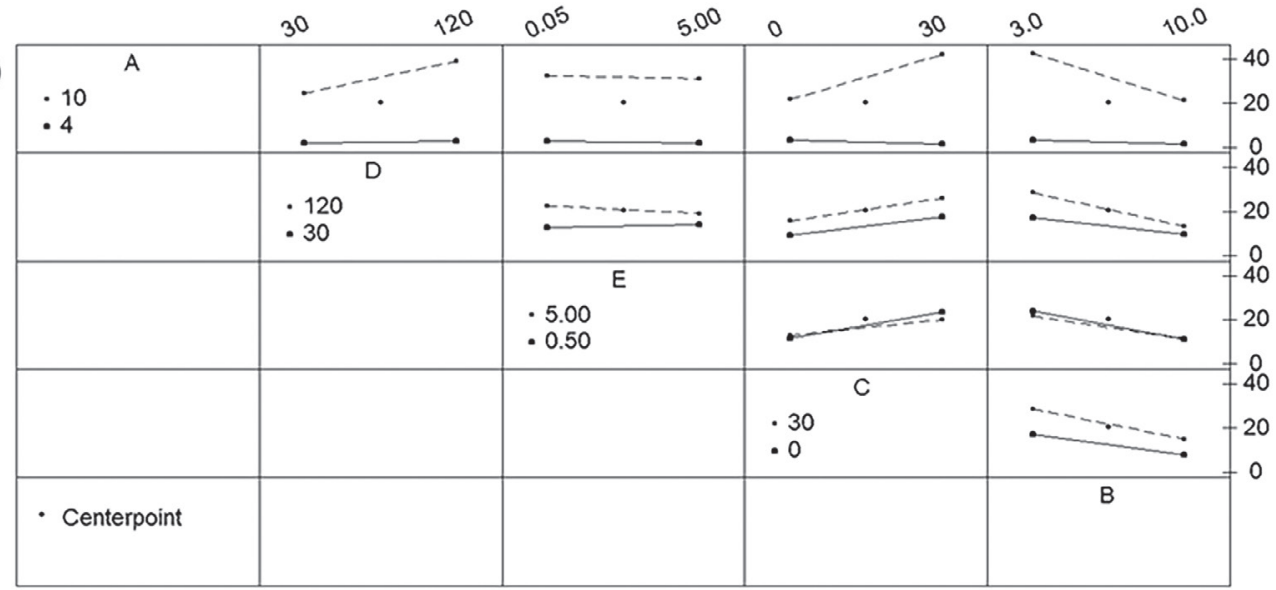

Figure 5. Graphics of interaction between factors: (a) SBSE(PDMS) and (b) SBSE(EG-Silicone).

best results attained using $30 \%$ of $\mathrm{NaCl}$. A hypothesis to explain this result is that, as norharman is an intermediate polarity compound, the addition of $\mathrm{NaCl}$ improves the ionic strength of the medium, causing a salting out effect and disturbing the partition equilibrium, leading to greater retention of norharman by the polymer phase. According to the main effects graph, the total sample volume was an important factor for both coatings. The optimized sample volume chosen was $3.0 \mathrm{~mL}$, and the norharman recovery rate was found to increase as the total sample volume decreased. This can be explained by the decrease in the phase ratio $(\beta)$. Phase ratio is the ratio of the total sample volume to the polymer phase volume $\left(\beta=\mathrm{V}_{\mathrm{W}} / \mathrm{V}_{\mathrm{PDMS}}\right)$, and the theoretical recovery (TR) rate increases as the phase ratio decreases, as described by equation $3 .{ }^{25}$ Thus, the experimental results depicted in Figure 3 are consistent with this theoretical equation.

$\operatorname{TR}(\%)=\left[\frac{\frac{\mathrm{K}_{\mathrm{O} / \mathrm{w}}}{\beta}}{\left(\frac{\mathrm{K}_{\mathrm{O} / \mathrm{W}}}{\beta}\right)+1}\right] \times 100$
Extraction time was not a key factor for any coating, but the best response was achieved in $120 \mathrm{~min}$. According to the literature, ${ }^{25}$ recovery rates are higher in response to increasing extraction time, until the analyte reaches equilibrium between the extracted sample and the polymeric coating.

According to the graphs of interaction between factors (Figure 5), there was no significant interaction between the factors under study. Therefore, the best values for the factors $\mathrm{pH}$, percentage of $\mathrm{NaCl}$ and total sample volume were defined independently, based on the results depicted in the Pareto chart and the main effects graphs. The best response was achieved using $\mathrm{pH} 10,30 \%$ of $\mathrm{NaCl}$ and $3 \mathrm{~mL}$ of total sample volume.

The percentage of methanol proved to be the least important factor, since it did not interfere in the norharman recovery rate at the different levels. Therefore, $5.0 \%$ of methanol was employed, since this percentage enables the different sample solutions to be prepared and handled with the least error.

The optimized conditions for norharman extraction were employed in the desorption study. The best desorption 
solvent was evaluated based on preliminary analyses using $60 \mathrm{~min}$ of ultrasonic bath and a solvent volume of $150 \mu \mathrm{L}$, and the best result was achieved with $100 \%$ methanol. After defining the desorption solvent, the desorption kinetics curves were drawn (Figure 6) in order to determine the best desorption time for SBSE(PDMS) and SBSE(EG-Silicone). The times evaluated were 2.5, 10.0, 15.0, 30.0 and $60.0 \mathrm{~min}$. The kinetics study indicated that the highest norharman recovery rate, with both PDMS and EG-Silicone coatings, was achieved at $15.0 \mathrm{~min}$.

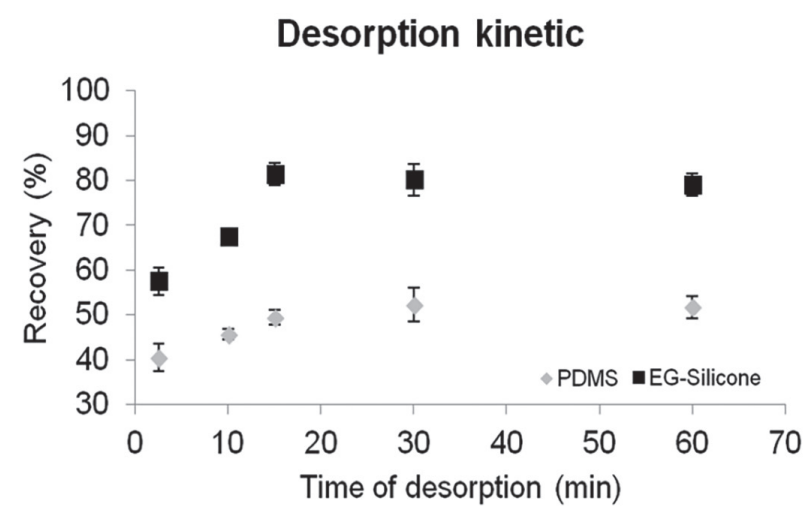

Figure 6. Kinetic of desorption of norharman for SBSE(PDMS) and SBSE(EG-Silicone) stir bars.

After defining the ideal extraction and desorption parameters, experiments were performed to determine which of the coatings provided the best norharman recovery rate. For these experiments, a concentration of $5.00 \mu \mathrm{g} \mathrm{L} \mathrm{L}^{-1}$ of a standard solution of norharman was used, and extraction were: $3.0 \mathrm{~mL}$ of total sample volume, $30 \%$ of $\mathrm{NaCl}$, $5.00 \%$ of methanol, $\mathrm{pH} \mathrm{10}$, and 120 min extraction time. The optimized parameters for desorption were $150 \mu \mathrm{L}$ of methanol and $15.0 \mathrm{~min}$. The recovery rate with the PDMS coating was $51.73 \%$, while that of the EG-Silicone coating was $80.54 \%$. Hence, the method was developed fully using only EG-Silicone stir bars, as follows.

Considering the SBSE optimized parameters, the preconcentration factor $(f)$ of the process is $f=8$. This value is obtained by calculating the ratio $\mathrm{f}=\mathrm{b} / \mathrm{a}$, where $(\mathrm{a}=$ initial amount of norharman utilized in the extraction experiment) and $(b=$ final amount of norharman, found in the vial of the final sample analyzed by HPLC-Flu).

The matrix effect of the $P$. edulis rinds on norharman extraction was also evaluated, based on two series of experiments performed with EG-Silicone stir bars, using the optimized extraction parameters. An evaluation was made of the recovery rate of the norharman standard $\left(5.00 \mu \mathrm{g} \mathrm{L}^{-1}\right.$, in methanol) with the addition of 100 or $50 \mathrm{mg}$ of rinds, in triplicate, according to equation 4 . The recovery rate in the extraction of $100 \mathrm{mg}$ of rinds was $(24.65 \pm 3.18) \%$, and with $50 \mathrm{mg}$ of rinds this rate was $(41.43 \pm 1.28) \%$. Given that this matrix showed a strongly negative influence on the recovery rate of the method, the standard addition method was adopted for quantitative analysis, using $50 \mathrm{mg}$ of $P$. edulis rinds.

$R(\%)=\frac{\left(A_{E}-A_{R}\right)}{A_{T}} \times 100$

where, $A_{E}=$ experimental area = area of the analyte after the extraction (standard + rinds); $A_{R}=$ experimental area of rinds = area of the analyte after extraction without standard and $\mathrm{A}_{\mathrm{T}}$ is:

$\mathrm{A}_{\mathrm{T}}=$ Theoretical area $=\frac{\left(\begin{array}{c}\text { area of the standard } \\ \text { before extraction }\end{array}\right) \times\left(\begin{array}{c}\text { total sample } \\ \text { volume }(\mathrm{L})\end{array}\right)}{\text { volume of desorption }(\mathrm{L})}$

\section{Analytical evaluation of the quantification method}

The analytical HPLC-Flu method used in these SBSE studies was evaluated in terms of its linearity, precision, accuracy, limit of detection (LOD) and limit of quantification (LOQ). Linearity was determined from the correlation coefficient of the analytical curve, which was $\mathrm{R}^{2}=0.9914$. The recovery rates ranged from 37.93 to $43.05 \%$, with an average of $39.78 \%$, and all the relative standard deviations (RSD) were below $5.00 \%$. The LOD and LOQ were 0.18 and $0.6 \mu \mathrm{g} \mathrm{L}-1$, respectively, considering the pre-concentration factor (f).

\section{Quantitative analysis of norharman}

Figure 7 shows a typical chromatogram of $P$. edulis rinds analyzed by the SBSE(EG-Silicone)-HPLC-Flu method. The analytical curve used for the quantification was built by spiking rind samples with the standard solution of norharman in the range of $0.25-0.75 \mu \mathrm{g} \mathrm{L}^{-1}$, and the curve equation obtained was $\left(y=4.54 \times 10^{6} x+1.27 \times 10^{6}, \mathrm{R}^{2}=0.9953\right)$.

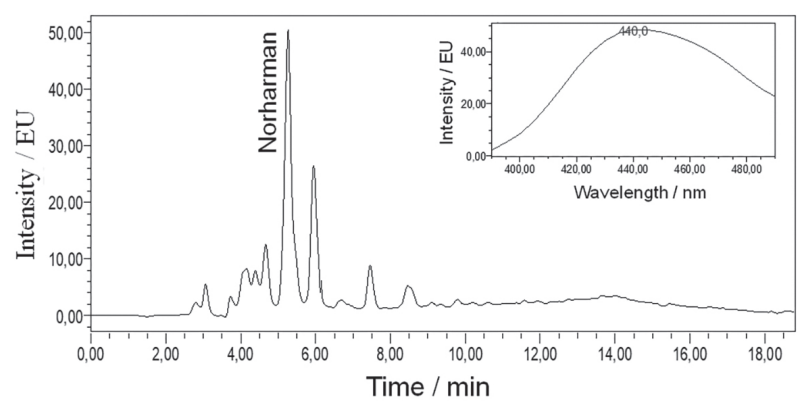

Figure 7. Typical chromatogram of $P$. edulis rinds extracts obtained by the optimized SBSE(EG-Silicone)-HPLC-Flu method described herein. 
The quantification showed $(332.16 \pm 8.43) \mathrm{pg} \mathrm{g}^{-1}$ of norharman in dried $P$. edulis rinds.

The consumption of dried passion fruit rinds, or passion fruit rinds flour, is growing in Brazil. In this country, where the industrialized product is known as "maracujá flour" (dried powdered rinds), it has become a popular functional food, as well as a source of bioactive compounds and a dietary supplement. Several studies ${ }^{4-7}$ have reported that dried rind extracts have health benefits for humans, but the data of the sample analyzed here suggest that about $33216 \mathrm{pg}$ of norharman is ingested upon consuming $100 \mathrm{~g}$ (ca. one tablespoon) of dried P. edulis rind in a meal. This estimate indicates the potential of $P$. edulis rinds as a source of $\beta$-carboline alkaloids. This amount may be higher depending on factors such as duration of the ingestion of this dietary supplement and the intake of norharman from other sources, e.g., food sources such as cocoa and coffee, ${ }^{16-18,35,38}$ and the environment, e.g., exposure to cigarette smoke. ${ }^{19,38}$ The intake of norharman from cocoa (ca. $84 \mu \mathrm{g}$ norharman $/ 100 \mathrm{~g}$ powdered cocoa $)^{38}$ and coffee (ca. $64 \mu \mathrm{g}$ norharman / $100 \mathrm{~g}$ powdered coffee) ${ }^{38}$ will be affected by the preparation process of the final product (chocolate, coffee drink), however. In view of the fact that some studies indicate that norharman and other $\beta$-carboline alkaloids may be neurotoxic, further investigations are needed considering the level of toxicity and bioavailability of norharman, considering aspects of food safety and the growing consumption of dried passion fruit rinds.

Lamounier et al. ${ }^{39}$ report the quantification of norharmane into infusions prepared with commercial samples of "passion fruit tea", containing P. alata Dryander, by micelar liquid chromatography-fluorimetric detection (218 ng of norharmane $+144 \mathrm{ng}$ of harmine in tea infusion prepared with two tea packages). Their results suggest that also phytotherapic preparations containing Passiflora should be deeper investigated.

\section{Conclusions}

This is the first report of norharman in P. edulis rinds using a SBSE(EG-Silicone)-UFLC-MS/MS method. The results of this study indicate that SBSE(EG-Silicone) combined with HPLC-Flu detection is a feasible method for the quantitative analysis of norharman in P. edulis fruit rinds. The performance of SBSE with EG-Silicone coating was superior to that of PDMS coating in the analysis of norharman, indicating that EG-Silicone stir bars can be used for compounds of higher polarity that are difficult to analyze using PDMS stir bars. The analytical determination of alkaloids in fruits is not easy because of the complexity of plant samples and the low amounts of these compounds into these complex matrices. However, the method presented here involves the use of small quantities of sample to identify and quantify norharman in a complex matrix. Its low LOD and LOQ and minimal sample handling make the method attractive. Moreover, given its automation and speed potential, SBSE(EG-Silicone)-UFLC-MS/MS may be an attractive method for screening numerous plant samples in future agronomic and phytochemical studies of $\beta$-carboline alkaloids, or even in routine quality control analysis by the food industry. The presence of norharman in dried sour passion fruit rinds suggests the need for further investigations into the safety of food containing passion fruit products.

\section{Acknowledgments}

The authors are grateful to Mr. Benedito M. dos Santos for technical assistance. J. H. Yariwake has received research grants from FAPESP (proc. 21886-7/2013) and CNPq (proc. 303667/2015-0). V. F. Freire has received a fellowship from CNPq (proc. 131094/2015-7).

\section{References}

1. Fogagnoli, G.; Seravalli, E. A. G.; Braz. J. Food Technol.. 2014, 17, 204.

2. Zeraik, M. L.; Yariwake, J. H.; Wauters, J.-N.; Tits, M.; Angenot, L.; Quim. Nova 2012, 35, 541.

3. Zeraik, M. L.; Serteyn, D.; Deby-Dupont, G.; Wauters, J. N.; Tits, M.; Yariwake, J. H.; Angenot, L.; Franck, T.; Food Chem. 2011, 128, 259.

4. da Silva, J. K.; Cazarin, C. B. B.; Bogusz Jr., S.; Augusto, F.; Maróstica Jr., M. R.; LWT - Food Sci. Technol. 2014, 59, 1252.

5. Farid, R.; Rezaieyazdi, Z.; Mirfeizi, Z.; Hatef, M. R.; Mirheidari, M.; Mansouri, H.; Esmaelli, H.; Bentley, G.; Lu, Y.; Foo, Y.; Watson, R. R.; Nutr. Res. 2010, 30, 601.

6. Watson, R. R.; Zibadi, S.; Rafatpanah, H.; Jabbari, F.; Ghasemi, R.; Ghafari, J.; Afrasiabi, H.; Foo, L. Y.; Faridhosseini, R.; Nutr. Res. 2008, 28, 166.

7. Zibadi, S.; Farid, R.; Moriguchi, S.; Lu, Y.; Foo, L. Y.; Tehrani, P. M.; Ulreich, J. B.; Watson, R. R.; Nutr. Res. 2007, 27, 408.

8. Dhawan, K.; Dhawan, S.; Sharma, A.; J. Ethnopharmacol. 2004, 94, 1.

9. Zeraik, M. L.; Pereira, C. A. M.; Zuin, V. G.; Yariwake, J. H.; Rev. Bras. Farmacogn. 2010, 20, 459.

10. Pereira, C. A. M.; Rodrigues, T. R.; Yariwake, J. H.; J. Braz. Chem. Soc. 2014, 25, 1472.

11. Freire, V. F.; Silva, G. R.; Yariwake, J. H.; J. Braz. Chem. Soc. 2018, 29, 775.

12. Tsuchiya, H.; Hayashi, H.; Sato, M.; Shimizu, H.; Iinuma, M.; Phytochem. Anal. 1999, 10, 247. 
13. Balón, M.; Hidalgo, J.; Guardado, P.; Muñoz, M. A.; Carmona, C.; J. Chem. Soc., Perkin Trans. 2 1993, 2, 99.

14. Tetko, I. V.; Gasteiger, J.; Todeschini, R.; Mauri, A.; Livingstone, D.; Ertl, P.; Palyulin, V. A.; Radchenko, E. V.; Zefirov, N. S.; Makarenko, A. S.; Tanchuk, V. Y.; Prokopenko, V. V.; J. Comput.- Aided Mol. Des. 2005, 19, 453.

15. Biagi, G. L.; Pietrogrande, M. C.; Barbaro, A. M.; Guerra, M. C.; Borea, P. A.; Cantelli Forti, G.; J. Chromatogr. A 1989, 469, 121.

16. Wojtowicz, E.; Zawirska-Wojtasiak, R.; Przygoński, K.; Mildner-Szkudlarz, S.; Food Chem. 2015, 175, 280.

17. Herraiz, T.; J. Agric. Food Chem. 2000, 48, 4900.

18. Koleva, I. I.; van Beek, T. A.; Soffers, A. E. M. F.; Dusemund, B.; Rietjens, I. M. C. M.; Mol. Nutr. Food Res. 2012, 56, 30.

19. Totsuka, Y.; Ushiyama, H.; Ishihara, J.; Sinha, R.; Goto, S.; Sugimura, T.; Wakabayashi, K.; Cancer Lett. 1999, 143, 139.

20. Esmaeili, M. H.; Movahedi, M.; Faraji, A.; Haghdoost-Yazdi, H.; Neurotoxicol. Teratol. 2012, 34, 489.

21. Haghdoost-Yazdi, H.; Hosseini, S.-S.; Faraji, A.; Nahid, D.; Jahanihashemi, H.; Behav. Brain Res. 2010, 215, 136.

22. Cao, R.; Peng, W.; Wang, Z.; Xu, A.; Curr. Med. Chem. 2007, $14,479$.

23. Baltussen, E.; Sandra, P.; David, F.; Cramers, C.; J. Microcolumn Sep. 1999, 11, 737.

24. Nogueira, J. M. F.; Anal. Chim. Acta 2012, 757, 1.

25. Nogueira, J. M. F.; TrAC, Trends Anal. Chem. 2015, 71, 214.
26. http://www.gerstel.com/en/twister-stir-bar-sorptive-extraction. htm, accessed in May 2019.

27. Ochiai, N.; Sasamoto, K.; Ieda, T.; David, F.; Sandra, P.; J. Chromatogr. A 2013, 1315, 70.

28. Gilart, N.; Miralles, N.; Marcé, R. M.; Borrull, F.; Fontanals, N.; Anal. Chim. Acta 2013, 774, 51.

29. Tanwar, S.; Di Carro, M.; Magi, E.; J. Pharm. Biomed. Anal. 2015, 106, 100.

30. Leardi, R.; Anal. Chim. Acta 2009, 652, 161.

31. Olariu, R.-I.; Vione, D.; Grinberg, N.; Arsene, C.; J. Liq. Chromatogr. Relat. Technol. 2010, 33, 1174.

32. Raynie, D. E.; Anal. Chem. 2010, 82, 4911.

33. Minitab Statistical Software, version 13; Minitab Inc., USA, 2000.

34. Eslami, Z.; Torabizadeh, M.; Talebpour, Z.; Talebpour, M.; Ghassempour, A.; Aboul-Enein, H. Y.; J. Chromatogr. Sci. 2016, $54,1652$.

35. Crotti, A. E. M.; Gates, P. J.; Lopes, J. L. C.; Lopes, N. P.; Mol. Nutr. Food Res. 2010, 54, 433.

36. Hibbert, D. B.; J. Chromatogr. B 2012, 910, 2.

37. ChemBioDraw Ultra, version 13.0; PerkinElmer Informatics, USA, 2012.

38. Pfau, W.; Skog, K.; J. Chromatogr. B 2004, 802, 115.

39. Lamounier, A. P.; Mateus, N. S.; da Cunha, A. L. M. C.; Luna, A. S.; Aucélio, R. Q.; J. Liq. Chromatogr. 2015, 38, 997.

Submitted: March 15, 2019

Published online: June 12, 2019 